DIRETOR DA FACULDADE DE CIÊNCIAS ECONÓMICAS:

Prof. Antônio Carlos Santos Rosa

VICE-DIRETOR: Prof. Nelson Rokembach

CHEFE DO DEPARTAMENTO DE CIENNCIAS ECONÓMICAS:

Prof. Renato Batista Masina

CONSELHO EDITORIAL: Prof. Pedro Cezar Dutra Fonseca (Presidente)

Prof. Achyles Barcelos da Costa

Prof. Carlos Augusto Crusius

Prof. Claudio Francisco Accurso

Prof. Edgar Augusto Lanzer

Prof. Ernani Hickmann

Prof. Nali de Jesus de Souza

Prof. Nuno Renan L. de Figueiredo Pinto

Profa Otilia Beatriz Kroeff Carrion

Prof. Roberto Camps Moraes

Profa Yeda Rorato Crusius

ANÁLISE ECONOMICA é uma publicação semestral da Faculdade de Ciências Econômicas da Universidade Federal do Rio Grande do Sul, visando divulgar estudos e pesquisas de seu corpo docente e discente na área de Economia. Aceitam-se, entretanto, artigos e resenhas bibliográficas de economistas e técnicos não vinculados à Instituição. As matérias assinadas são de responsabilidade exclusiva dos autores. É permitida a reprodução parcial para fins didáticos.

Toda a correspondência, material para publicação, assinaturas e permutas devem ser dirigidas a:

Prof. PEDRO CEZAR DUTRA FONSECA

Revista Anál ise Econômica

Avenida João Pessoa, $52-3^{\circ}$ andar

90.000 - Porto Alegre (RS) - Brasil 


\section{BASE TEÓRICA PARA INTERPRETAÇĀO DO PROGRESSO TÉCNICO E PROCESSO DE TRABALHO NO CAPITALISMO A PARTIR DE MARX}

INTRODUC̣ĀO

Edemar J. Buzanello * Silvio A. F. Cário **

O sistema capitalista constitui desde seu surgimento um modo de produção de transformação dinâmica no processo de trabalho. A medida que evoluiu, desde os primórdios anos de 1500, o trabalho foi gradativamente se subord inando ao capital. A passagem da subordinação formal do trabalho para o estágio adiantado da subordinação real ao capital nos dias atuais rompeu determinadas relações técnicas e sociais que fizeram da força de trabalho, de simples mercadorias a apêndice dos intrumentos de trabalho.

As transformações no processo de trabalho ocorreram dentro de uma estrutura historicamente determinada, que ERBER sintetizou da seguinte forma:

"1) a subordinação de grande número de trabalhadores a um capitalista, sem alterar os meios de produção anteriormente utilizados e mantendo o controle da técnica de produção nas mãos dos trabalhadores, quer seja na forma de putting out, quer seja reunindo os trabalhadores no mesmo local de trabalho;

2) o processo de trabalho passa a ser subdividido e as tarefas individuais simplificadas e sistematizadas do mesmo tempo que desenvolvem-se instrumentos especiais para cada operação;

3) finalmente os instrumentos manuais são substituídos por máquinas (mais tarde também fabricadas por meio de outras máquinas), que vão

Mestre em Sociologia Rural - IEPE e Prof : Dept. Ciências Sociais/UFSC
Mestre em Economia - IEPE e Prof. Depto de Ciências Econômicas/UFSC

ANALISE ECONÓMICA

ANO II

NO 3

MAR/1984

p. $19-37$ 
servir de elemento organizador da produção, transformando o trabalhador num apêndice e servidor da máquina". ${ }^{1}$

Os trabalhadores perderam o domínio sobre o processo de trabalho e concomitantemente, o capital transformou os instrumentos de trabalho, em armas necessárias para seu processo de acumulação. $O$ desenvoivimento das forças produtivas e a reprodução ampliada do capital são condições necessárias para a permanência do capitalista no sistema. A acumulação torna-se obrigatória e inerente ao capitalismo. "A acumulação não é, portanto, uma questão de escolha individual. Trata-se de uma necessidade engendrada pela própria competição: uma luta em que os capitalistas procuram excluir-se uns aos outros do mercado. O progresso técnico é a arma utilizada por esses senhores para se esmagarem mutuamente. Mediante a introdução đe inovações procuram rebaixar seus custos e aumentar suas margens de lu$\mathrm{cro"}^{\prime \prime}{ }^{2}$ )

A visão marxista deste processo realça claramente a forma com que o capitalismo busca no trabalho excedente a sua valorização. Transforma os instrumentos de trabalho numa luta intercapitalista e procura diminuir o tempo de trabalho necessário. Ao assim fazê-lo conduz não só à coletivização do processo de trabalho, mas também à separação do trabalho mental e manual, simplificação de tarefas, hierarquização da produção e controle rígido dos procedimentos dos trabalhadores frente ao processo de trabalho.

Este "paper" pretende justamente trazer a discussão contemporânea às transformaç̃os citadas por Marx a 100 anos atrás. $O$ capitalismo tem sofrido verdadeiras transformaç̃̃es no processo de trabalho e no progresso técnico, e a visão dinâmica e social apontadas por Marx, com intuito de demonstrar as leis e as contradições, são importantes para o debate e o verdadeiro entendimento do seu funcionamento.

No item sobre Organização do Processo de Trabalho na Cooperação e Manufatura, discute-se as principais conseqüências da divisão do trabalho na relação en tre capital $x$ trabalho.

Nas transformações dos Instrumentos de Trabalho na Fábrica Moderna, apresenta-se a importância do progresso técnico na criação da maisvalia relativa.

E, finalmente, no item O Progresso Técnico e Processo de Trabalho na Acumulação Capitalista, expõem-se a necessidade do sistema em desenvolver as forças produtivas para estimular o processo de concentração e

1 ERBER, F. Processo de trabalho e estratégia de classe. Zahar, RJ, 1982, p. 2.

${ }^{2}$ BERLUZZO , L. G. M. Valor e capitalismo, Brasiliense. SP, 1981, p 92. 
centralização de capital. Consubstancia-se as concepções de Marx sobre esta temática, com os estudos contemporâneos de Mandel e Labini.

Salienta-se ainda, que este "paper" não discute a teoria do valor, pois seu principal objetivo é explicar as transformações e os efeitos no processo de trabalho e no progresso técnico imposto pelo sistema capitalista.

\section{ORGANIZAC̣ÃO DO PROCESSO DE TRABALHO NA COOPERAC̣ĀO E MANUFATURA}

O surgimento do sistema capitalista deu-se a partir do rompimento do sistema feudal, no qual surgiram determinadas características até então inexistentes no modo de produção anterior. Dentre estas ,destaca-se o comportamento da força de trabalho, que passou a ser uma mercadoria livremente vendida no mercado. Segundo BRAVERMAN, "a força de trabalho converteu-se numa mercadoria, suas utilidades não mais são organizadas de acordo com as necessidades e desejos dos que a vendem, mas antes de acordo com as necessidades de seus compradores que são, em primeiro lugar, empregadores à procura de ampliar o valor do capital".3)

A liberdade da força de trabalho irrompeu com o capitalismo, pois nos sistemas anteriores existia a vinculação total ou parcial dos trabalhadores aos seus proprietários. Na escravidão, o amo nẽo só era proprietário dos meios de produção como também da força de trabalho. No feudalismo, o senhor era proprietário da terra e o servo deveria trabalhar gratuitamente certas quantidades de dias por ano. Já no capitalismo ocorre uma separação entre o proprietário dos meios de produção e o trabalhador, devendo este vender sua força de trabalho para sobreviver.

A nova característica da força de trabalho configurou-se a partir de determinadas circunstâncias. As cortes numerosas e tropas dos senhores feudais tornaram-se supérfluas e dispendiosas, a expulsão dos camponeses e pequenos proprietários das terras de plantio, além do crescimento populacional, resultaram na criação de numerosos proletários "livres" que se colocavam à disposição do novo sistema vigente. Verificava-se a presença dos artesãos mais bem sucedidos que aumentavam suas oficinas e o número de aprendizes e semi-operários e pessoas que ao emigrarem para as cidades dedicavam-se a diferentes tipos de trabalho.

O aparecimento no mercado de uma nova mercadoria (força de trabalho) aliada a outros fatores (expropriação dos pequenos produtores, ex-

\footnotetext{
${ }^{3}$ BRAVERMAN, H. Trabalho e capital monopolista - degradação do trabalho no século $X X$.
} Zahar. RJ. 1977 , p. 79 
ploração simultânea do capital comercial dos produtores e consumidores) geraram condições para a acumulação primitiva do capital, que serviu de base para o in ício das primeiras cooperações. $\left.{ }^{4}\right)$

As cooperações, denominadas por Marx como "a forma de trabalho em que muitos trabalham juntos, de acordo com um plano, no mesmo processo de produção ou em processos de produções diferentes, mas cone$x^{\prime \prime \prime 5)}$, caracterizou a fase inicial de como os primeiros capitalistas organizavam o processo de trabalho.

O objetivo estava imbutido na concepção de fusão de muitas forças numa força comum, pois o trabalho em conjunto provoca emulação entre os participantes, animando-os e estimulando-os no intuito de aumentar a capacidade produtiva de cada trabalhador. Esta observação deriva de que o processo de trabalho mesmo sendo integralmente feito por um trabalhador, se reunido aos demais, produziria mais do que isoladamente. Aliado a este objetivo, tinha-se a redução do espaço, concentração dos meios de produção e eliminação de uma série de custos dispensáveis no processo de trabalho.

O crescimento da cooperação de assalariados estava vinculado com a expansão na concentração dos meios de produção que exigia um maior domínio do capital para execução do processo de trabalho. Esta condição de direção e supervisão das atividades individuais são compreendidas pelo capitalista, ". . . a função de dirigir, superintender e mediar assume-a o capital logo que o trabalho a ele subordinado se torna cooperativo". ${ }^{1}$ )

Marx justifica este controle pela necessidade do capitalista atender seu principal objetivo, qual seja, a maior expansão possível do capitál. Para tanto, organiza o processo de trabalho no sentido de obter a maior produção possivel de trabalho excedente.

A partir do momento em que a supervisão é insuficiente frente ao crescimento ampliado da cooperação, delega-se funções a determinados trabalhadores que comandam o processo de trabalho em nome do capital. "Com o desenvolvimento o capitalista se desfaz da função de supervisão direta e contínua dos trabalhadores isolados e dos grupos de trabalhadores, entregando-a a um tipo especial de assalariado. Do mesmo modo que um exército, a massa de trabalhadores que trabalha em conjiunto sob o comando do mesmo capital precisa de oficiais superiores (dirigentes, gerentes) e sub-

\footnotetext{
4 LAPIDUS \& OSTROVITIANOV. Princípios de economia política. Aldeia Global, BH., 1979, p. 10 e 11 .

5 MARX, K. O capital Civ. Bras. RJ. Livro 1 vol 1, 1978, p. 374

6 MARX, K. O capital, op. cit. p. 380 .
} 
oficiais (contramestres, inspetores, capatazes) que durante o processo de trabalho comandam em nome do capital". ?)

O processo de trabalho desenvolvido sob estas circunstâncias na cooperação, se propaga com novos incrementos no periodo manufatureiro. E na cooperação que se verifica a primeira fase de subordinação do trabalho ao capital, apesar da divisão do trabalho e do progresso técnico não desempenharam papéis importantes neste período.

Se, na cooperação, os trabalhadores eram reunidos sob um mesmo teto para realizarem isoladamente o processo de trabalho, na manufatura, ofícios isolados e independentes perdem tais características e conjuntamente, como trabalhadores parciais de um mesmo processo produtivo, executam tarefas que na sua totalidade resultará num produto final. Cada operação do processo de trabalho depende exclusivamente de um trabalhador e a sua totalidade é executada pelo somatório dos trabalhadores parciais. ${ }^{8}$ )

A manufatura apresenta do is aspectos importantes: “. . . de um lado, surge a combinação de ofícios independentes diversos que perdem sua independência e se tornam tão especializados que passam a constituir apenas operações parciais do processo de produção de uma única mercadoria; de outro, tem sua origem na cooperação de artífices de determinado ofício, decompondo o ofício em suas diferentes operações particulares, isolando-as e individualizando-as para tornar cada uma delas função exclusiva de um trabalhador especial". 9 )

A divisão do trabalho assume proporções significativas com as operações parciais e perda da independência dos ofícios. Apesar do processo de trabalho continuar ainda sendo manual, dependendo da destreza e habilidade do trabalhador em manejar seus instrumentos de trabalho, este ainda possui em parte domínio sobre os instrumentos de trabalho.

O domínio se configura pelo ritmo imposto no processo de trabalho, no qual em determinadas operações o trabalhador tem mais energia, noutras mais habilidade, concentração, etc., possibilitando assim aumentar sua criatividade.

O trabalho parcial constitui um artífice do capitalista no intuito de obter maior produtividade em menor tempo no processo de trabalho. A repetição contínua da mesma ação ensinará a alcançar a produção desejada,

\footnotetext{
7 MARX, K. O capital, op. cit. p. 381

8 Stepeen Marglen', conclui' que foi separando as tarefas' destinadas a cada operário, que o capitalista pôde antes da introdução de máquinas dispendiosas, assegurar o controle da produção em

Origens e funções do parcelamento das tar
MARX, K. O capital, op. cit. p. 388 e 389
} 
em substituição ao trabalhador que executa diferentes operações. Ao assim fazêto, gera uma mutilação na real capacidade da força de trabalho. "A manufatura produz realmente a virtuosidade do trabalhador mutilado, ao reproduzir e levar sistematicamente ao extremo, dentro da oficina à especialização natural dos ofícios que encontram na sociedade". ${ }^{1}$ 0)

A razão desta concepção de Marx se traduz no fato de que o trabaIhador ao limitar-se única e exclusivamente a determinada função no proces. so de trabalho, torna-se parte integrante de um mecanismo global como uma simples peça de uma máquina. Desta forma, os capitalistas transformam os seres humanos a simples membros de um mecanismo que a ele pertence e Ihe deve submissão incondicional. Esta relação entre o capital e o trabalho, foi outrora expressa por Smith ${ }^{11}$ ) quando admitiu que a especialização advinda da divisão do trabalho, que a rigor aumenta a riqueza das nações, tem a tendência de mutilar culturalmente o trabalhador, tornando mais restrita sua capacidade produtiva.

A divisão do trabalho imposta na manufatura apresenta três características: a) o trabalhador serve-se de sua ferramenta b) o movimento do instrumento de trabalho parte do trabalhador e, c) o trabalhador forma com outros membros um mecanismo vivo. O capitalista desmonta o ofício e o restitui aos trabalhadores parcelados, de modo que o processo de trabalho, como um todo, já não seja mais da competência de um trabalhador indivi dual. ${ }^{12)}$

Ao impor a perda da independência de cada ofício e fazendo-o parcelar, a divisão exige que o resultado de um trabalhador seja ponto de partida para o trabalhao seguinte, para tanto, a experiência e o tempo de trabaIho em cada fase devem ser alocados de tal forma que as diferentes fases do processo de trabalho se completem sem interrupção.

O ritmo imposto pelo trabalho parcelar requer devidamente a proporcionalidade na alocação da força de trabalho com os instrumentos de trabalho. Neste sentido, o capitalista, imbuído na crescente valorização do seu capital, amplia concomitantemente os elementos componentes do

10 MARX, K, O capital, op. cit p. 390

11 Smith afirma: "a mente da maioria dos homens desenvolve-se necessariamente de e por suas ocupaçôes costumeiras. Um homem que passa toda a vida a executar algumas operações simples, não tem oportunidade de usar a inteligência. Torna-se em geral tẫo estrípido e tão ignorante quanto possa tornar-se uma criatura humana. . Destrói-lhe até a energia do corpo e torna-o incapaz de usar sua força com vigor e perseverança a não ser na ocupaçấo fragmentada a qual foi destinado". in WEISS, Donald W. Marx X Smith sobre a divisão do traba/ho, Montly Review - NY vol. 28, no 3, jul/ago 1976

12 BRAVERMAN, H. T. Trabalho e capital monopolista: a degradação do trabalho no século $X X$, op. cit p. 148-159. 
capital constante e variável, porém em proporções maiores o primeiro em relação ao segundo.

Dentro deste ritmo o capital cria uma gradução hierárquica entre os trabalhadores, exigida pelas diferentes tarefas oriundas do parcelamento no processo de trabalho, escondendo por detrás desta concepção, a ordem e a disciplina que os trabalhadores deverão submeter-se. Ao assim fazể-lo, as diferentes funções são categorizadas, em simples e complexas, fáceis e difíceis, exigindo portanto da força de trabalho diferentes níveis de valores que são expressos numa escala correspondente de salários. ${ }^{13}$ )

A hierarquização constitui a forma com que o capital pode alcançar não só maior produtividade, mas também, o barateamento da força de trabalho. "Tanto quanto o trabalho pode ser dissociado, pode ser separado em elementos, alguns dos quais são mais simples que outros e cada qual mais simples que o todo. Traduzindo em termos de mercado, isto significa que a força de trabalho capaz de executar o processo pode ser comprada mais barato como elementos dissociados do que como capacidade integrada num só trabalhador".14)

Dentro desta estrutura, reluz a importância da coletivização do trabalho, expressando a organização social da produção, em que todos trabaIham em prol dos objetivos expressos pelo capital. A organização do processo de trabalho representa para o capitalista a forma de aumentar seus ganhos, notadamente através não só do domínio sobre o processo de trabalho, mas também pela elevação do tempo de trabalho suplementar. Com intensificação do processo de trabalho, a força de trabalho requer menos tempo necessário de produção para sua reprodução. A redução do tempo de trabalho necessário e o prolongamento do trabalho suplementar proporciona condições para expansão do valor do capital.

Torna-se importante o capital na concepção marxista transformar as condições técnicas e sociais do processo de trabalho, a fim de aumentar a força produtiva do trabalho, só assim, pode diminuir o valor da força de trabalho e reduzir a parte do dia de trabalho necessária para reproduzir esse valor". . . . . . justamente para ampliar a outra parte durante o qual pode trabalhar gratuitamente para o capitalista".15)

13 GORZ, André. Crítica da divisão do trabalho, Martins Fontes, SP, 1980, p. 24.25:

14 As concepçסes de C. Babbage, On the economy of mochinery and manufactures, 1835 estão resumidos nas palavras de BRAVERMAN, H. Trab, e capital monopolista; a degradação do trabalho no século $X X$, op. cit. p. 79

15 MARX, K. O capital, op, cit. p. 362 e 269. 
Todo esforço do capitalismo, a partir da manufatura, se concentrou basicamente na criação de meios e condições para a reprodução da maisvalia relativa. A partir disto, dois aspectos devem ser considerádos: o primeiro, está embutido na relação direta do crescimento da mais-valia relativa com o desenvolvimento da produtividade do trabalho e em segundo, a relação inversa com o valor das mercadorias. Assim, a unidade da produção e consumo é preservada, solucionando com o barateamento das mercadorias a realização no mercado da mais-valia originada na produção.

Urgiu ao capitalismo a necessidade de acelerar o desenvolvimento das forças-produtivas frente não só de atender estes objetivos expostos, mas para contrapor as restrições impostas pelos limites físicos da força de trabatho e da luta política da classe trabalhadora pela redução da jornada de trabalho.

A considerar estes aspectos, o capitalismo ultrapassa seus limites de organização do processo de trabalho para as radicais transformações nos instrumentos de trabalho, com o advento da fábrica moderna.

\section{TRANSFORMAC̣ŌES DOS INSTRUMENTOS DE TRABALHO NA FĀBRICA MODERNA}

O desenvolvimento do sistema de máquinas e equipamentos tornou possível atender a exigência do capital na produção incessante de maișvalia relativa, ao exigir do trabalhador maior incremento no processo de trabalho.

O instrumento de trabalho é retirado das mãos do trabalhador e transferido para um determinado mecanismo acionado por energia que transmitida à ferramenta, atua sobre a matéria-prima no intuito de obter o produto final. Estes agora novos instrumentos de trabalho são transformados em função de obterem maior potência, velocidade e perfeição. Estas transformações segundo Marx, coloca aos olhos do capitalista significativa diferença nas quantidades de mercadorias produzidas, embora ainda o tra. balhador continue sendo o ponto de partida de todo o processo de trabalho.

Aș limitações e as imperfeições da força de trabalho em produzirem determinados movimentos, são substituídas pelos instrumentos de trabalho (motor) que impulsionam inúmeras máquinas ao mesmo tempo, demonstran. do as grandes proporções que um mecanismo de transmissão pode alcançar, no intuito de se obter maior produtividade. Esta dinâmica exige uma organização do capital na alocação adequada dos instrumentos de trabalho em cada fase do processo produtivo. A exemplo da manufatura que exigia 
determinadas proporções entre grupos de trabalhadores parciais por tarefas, - sistema de máquinas na fábrica moderna requer combinações adequadas entre o número, tamanho e velocidade das máquinas.

A produção torna-se mecanizada na sua forma mais desenvolvida, recebendo de Marx certas comparações. "Surge, então em lugar da máquina isolada, um monstro mecânico que enche edifícios inteiros e cuja força demoníaca se disfarça nos movimentos ritmados quase solenes de seus membros gigantes ritmados e irrompe no turbilhão febril de seus inúmeros órgãos de trabalho".16)

A transformação no modo de produção se propaga a diferentes ramos que apresentam cèrtas independências como uma necessidade lógica da expansão capitalista. ${ }^{17}$ )

A dinamicidade alcança seu máximo, quando o capitalismo reproduz de forma ampliada seu principal instrumento de trabalho, a produção de máquinas com máquina.

O departamento I, produção de bens de capital, vem a constituir - motor dinâmico da economia capitalista e base para sua reprodução. Concentra-se hegemonicamente esforços para o desenvolvimento das forças produtivas neste setor, cuja irradiação se propagará para o departamento II, produção de bens de consumo. Neste processo, nada é considerado definitivo e permanente. Os produtos são inventados e transformados no intuito de atender os anseios do capital.

As transformações nos instrumentos de trabalho, movida pela busca incessante do capital auto valorizar-se conduz, pela própria lei da dialética, a contradição na sua relação com a jornada de trabaltho. Se, por um lado, com a maquinaria ocorre uma diminuição na jornada de trabalho, por outro, com sua presença, ". . . o capital înduz o trabalhador a empregar realmente maior força de trabalho . . . impõe mais elevada tensão da força de trabalho, preenchimento mais denso dos poros da jornada, em suma, um tal grau de condensação do trabalho que pode ser alcançado reduzindo-se o dia de trabalho".18) O capital perde em duração da jornada de trabalho, mas em contrapartida compensa pela eficácia no processo de trabalho.

O rítmo de trabalho imposto pela máquina exige da força de trabalho um acompanhamento contínuo e rigoroso dos seus movimentos.

\footnotetext{
16 MARX, K. O capital, op. cit.p. 435.

17 A exemplo disto, Marx observa que a mecaniżação da fiação tornou necessária a mecanização da tecelagem e ambas acionaram transformações na indústria química.

18 MARX, K. O capital, op. cit. p. 468
} 
Nos setores mais automatizados têm-se um número maior de máquinas e equipamentos sendo controlados por um só trabalhador.

A medida que o capitalismo avança, as diferenças entre habilidades da força de trabalho em acompanhar, supervisionar os instrumentos de trabalho diminuem, tornando-se menos pronunciadas. As habilidades para fazer o produto $B$ tornam-se praticamente semelhantes para a produção de $C$, pois quaisquer que sejam as habilidades requeridas para vigiar uma máquirı de produção $B$, não serão significativamente diferentes daquelas envolvidas em controlar uma máquina de produção $\mathrm{C}$.

O desenvolvimento das forças produtivas tem levado a uma automação do processo de trabalho, as máquinas e equipamentos se encarregam da produção, exigindo da força de trabalho apenas serviços de vigiar e manu. tenção.

Por um lado, a automação traz para o capitalista maior eficiência e lucros, de outro, conduz o trabalhador a um apêndice do maquinarismo. As únicas operações reservadas ao operário reduzem-se aos serviços auxiliares de vigilância, de correção das operações mecânicas e de alimentação da máquina. Além disso, uma parte cada vez maior das funções manuais residuais é, pouco a pouco, mecanizada e incorporada às máquinas. ${ }^{19}$ )

A base técnica da manufatura expressa por Marx é ultrapassada na fábrica moderna. Se na primeira, o trabalhador servia o instrumento de trabalho e fazia parte de um mecanismo vivo, na segunda, serve a máquina e são complementos vivos de um mecanismo morto.

A supremacia dos instrumentos de trabalho conduziu a despersonalização e desumanização da força de trabalho. O processo de trabalho é desenvolvido por tarefas que não permitem criatividades e requerem cada vez menos especificidades na função. O capital separou a mente do coração da fábrica. Os instrumentos e processos de trabalho são inventados fora do setor produtivo e neste, as pessoas dispendem suas vidas em tarefas monótonas que não permitem o empenho de sua capacidade e inteligência. Caracterizase na indústria moderna, a separação entre as forças de trabalho intelectuais e as engajadas no trabalho manual. Toda a habilidade e experiência do trabalhador fica despojada frente a esta divisão social do trabalho imposta pelo capital. O poder decisório do capitalismo e a revolução científica e tecnológica reduz estas características do trabalhador a pequenas proporções.

19 PALMA, Armando de A organização capitalista do trabalho em, o capital de Marx in A divisäo capitalista do trabalho. Iniciativas Ed., Lisboa, 1976 p. 46. 
A graduação advinda da separação entre as fases em que são distribuídos os trabalhadores junto às diferentes máquinas especializadas é hierarquizada. Através de sua participação no processo de trabalho e no grau que está colocado na hierarquia ocupacional, a força de trabalho obtém sua remuneração para a reposição das energias gastas durante a jornada de trabalho.

O aperfeiçoamento dos instrumentos de trabalho visa segundo o raciocínio marxista, substituir o trabalhador mais qualificado e redundar em menos dispêndio para o capital. A partir do momento em que a máquina realiza praticamente todo processo de trabalho, o trabalhador hábil deixa de ter sua função, sendo substituído pelo menos hábil cujo salário é inferior.

$O$ instrumento de trabalho ao tomar a forma de máquina, se tornou concorrente do próprio trabalhador. O valor de troca da força de trabalho diminuiu com o desvanecer de seu valor de uso.

$\mathrm{Na}$ expansão do progresso técnico, o capital apropria-se gradativamente das forças de trabalho suplementar, colocando a sua mercê, todos os membros da família e obtendo com isto maior produtividade com a repartição do valor da força de trabalho do homem pela família inteira. ${ }^{20}$ )

A crise econômica e o conjunto de ideologia de libertação na sociedade capitalista contribuem para que todos os elementos da família venham a participar do processo produtivo, garantindo assim maior produtividade social e condições para a realização do trabalho excedente no mercado consu. midor. ${ }^{21)}$

A transformação dos instrumentos de trabalho trouxe para a classe trabalhadora não apenas um concorrente, mas também, constituiu instrumento para reprimir as manifestações dos trabalhadores contra o despotismo do capital. "A máquinas não é apenas concorrente todo-poderoso, sempre pronto a tornar supérfluo o assalariado. O capital aberta e tendenciosamente proclama o poder inimigo do trabalhador, manejando-a em função desse atributo. Ela se torna a arma mais poderosa para reprimir as revoltas

20 Marx observa que com a compra de quatro forças de trabalho referente a familia, custa mais ao capital do que somente a força de trabalho da famllia, mas obtém quatro jornadas de trabalho em lugar de uma. O preço da força de trabalho diminui na proporção em que o trabalho excedente dos quatro ultrapassa o trabalho excedente de um in $O$ capital, op cit p. 450.

21 Segundo BRAVERMAN, H. Trabalho e capital monopolista: A degradação do trabalho no século $X X$, op cit p 331, o trabalho feminino tem expandido mais que o masculino, demonstrando que o mercado de trabalho apresenta certa repulsão à força de trabalho masculino e atração da feminina em escata elevadíssima. Porque será? Necessidade? Trata-se da maior participação da mulher na sociedade? Tais questôes encontram respostas em Marx. O interesse do capital em remunerar inadequadamente a força de trabalho conduz a sociedade para a "acumulação da miséria". A força de trabalho suplementar constitui uma forma de escravidão contemporânea. 
periódicas e as greves dos trabalhadores contra a autocrítica do capital". 22)

Ao diminuir o valor de troca da força de trabalho, ao aproveitar a força de trabalho suplementar, ao introduzir de forma crescente a automação no processo de trabalho, utilizando a até como instrumento repressivo, o capital criou um exército industrial de reserva que se coloca à sua disposição nos momentos por ele requerido.

O exército industrial de reserva da força de trabalho constitui o ápice das conseqüências advindas sobre o trabalhador, uma vez nele inserido o mesmo não tem como configurar o valor de uso e de troca de sua mercadoria. A dependência destes valores para sobreviver, faz com que o trabalhador submeta aos ditames do capital.

O exército industrial tende a crescer em contradição com o desenvolvimento das forças produtivas, alocando-se em diferentes ocupações; a fim de garantir sua sobrevivência. Estas ocupações são caracterizadas por taxas inferiores de salário, conduzindo a força de trabalho a niveis degradadores de condições de vida, principalmente os inseridos sob a categoria de estagnária. ${ }^{23}$ )

Independente da forma que se apresenta, a população trabalhadora excedente é inerente ao processo de acumulação de capital. Apresenta-se disponível às necessidades requeridas na expansão capitalista, alocando-se nos setores em crescimento, sem prejudicar as escalas de produção de outros, como também, nos períodos de crise, desempenha papel de intimidação fora da fábrica, perante as reivindicações dos que estão dentro da fábrica.

As transformações crescentes nos instrumentos de trabalho no sistema capitalista, têm se constituído fator necessário para seu desenvolvimento, no entanto, a sua contradição é expressa através da ". . . exploração civilizada e refinada da força de trabalho".24)

22 MARX, K O capital, op cit p. 499

23 Marx distinguiu três fontes de exército industrial de reserva: a) flutuante - força de trabalho excedente gerada pelo movimento da tecnologia e do capital nos centros urbanos, b) latente - força de trabalho excedente que se encontra nas zonas agrícola e, cl estagnária - "constitui parte do exército de trabalhadores em ação mas com ocupação totalmente irregular . . . . . duração máxima de trabalho e minimo de salário caracterizam sua existência. Encontram-se em ramos especiais de exploração do capital in $O$ capital, p. 743-747.

24

GORZ, André Crítica da divisáo do trabalho, op. cit. p. 29. 
O PROGRESSO TÉCNICO E O PROCESSO DE TRABALHO NA ACUMULAC̣ÃO CAPITALISTA

A submissão real do trabalho ao capital configura-se no estágio mais avançado do capitalismo. A mais-valia relativa é a forma do capital sobrepor-se ao trabalho no intuito de obter um valor superior ao aplicado inicialmente. A transformação deste novo valor em capital constitui a lei geral da acumulação capitalista.

Segundo Marx, "a conversão contínua da mais-valia em capital se patenteia na magnitude crescente do capital que entra no processo de produção e se torna base da produção em escala ampliada, dos métodos que a acompanham para elevar a força produtiva do trabalho e acelerar a produção de mais-valia." 25$)$ O excedente gerado constitui a base para a acumulação de capital que dinamicamente repete em escala ampliada, requerendo para tanto, subordinar o trabalho a seus interesses.

Diferentemente da subordinação formal onde a força de trabalho apesar das elevadas horas dispendidas no processo de trabalho possuía domínio parcial sobre os instrumentos de trabalho, a subordinação real do trabalho ao capital, reduz a primeira característica e mutila a segunda. Nesta nova configuração, ocorre a diminuição na jornada de trabalho, porém, verifica-se maior intensificação no processo de trabalho.

O desenvolvimento das forças produtivas constitui o principal instrumental para concretização desta subordinação, uma vez que o aumento da produtividade do trabalho reflete no máximo possível de trabalho não pago.

A transfiguração deste processo se consubstancia através do movimento de acumulação e reprodução do capital. A sua dinamicidade reflete numa luta inter-capitalista; onde a estrutura técnica sofre modificações crescentes, objetivando alterar a escala de produção.

O progresso técnico, como expressão das modificações que ocorrem na estrutura técnica do capital depende da relação que se interpõe entre a acumulação e a sua reprodução. A geração do excedente obtido no processo produtivo que cria condições para a ampliação do mesmo.

As forças produtivas expressas no aprimoramento técnico dos instrumentos de trabalho e no aperfeiçoamento da força de trabalho desenvolvemse no transcurso da história e dependem da estrutura de produção da socie-

25

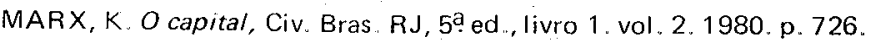


dade. O próprio Marx observa que o entendimento da produção de uma socidade deve ser buscada basicamente não no que se faz, mas como e com que instrumentos se faz. As condições econômicas e sociais impostas pelo capitalismo permitem as descobertas cientificas e suas aplicações. No modo de produção capitalista, a produção dos bens materiais ocorre sob a exploração da força de trabalho e ao assim fazê-lo proporciona a geração de excedentes que serão canalizados para o desenvolvimento das forças produtivas.

A aceleração e reprodução deste processo depende do volume de acumulação de capital. Os maiores capitalistas destinarão cada vez mais excedentes para o desenvolvimento científico e tecnológico das forças produtivas. ${ }^{26)}$

Os avanços que o capitalismo faz em sua estrutura, são concentrados. A concentração de capital expressa através da aquisição de novas máquinas e equipamentos transforma a base produtiva e cria condições para não só obter uma maior valorização do capital como também possibilitar o processo de centralização do capital. A concentração possibilita a existência de condições para a redução do número de capitalistas.

A medida que o modo de produção capitalista avança verifica-se o elevado volume de capital se concentrar nas mãos de um número cada vez menor de capitalistas. A competição inter-capitalista movida pelo progresso técnico coloca os grandes capitalistás em situações privilegiadas em relação aos demais que não conseguem acompanhá-tos.

A concentração e centralização do capital em escalas crescentes possibilitam elevados níveis de produção, diferenciações e qualidades nas mercadorias produzidas, objetivadas a conseguirem num espaço de tempo reduzido a realização da mais-valia no mercado.

O mecanismo concentrador e centralizador do capital traz no seu interior o aumento da composição orgânica do capital. Expressa-se o crescimento do capital constante, na qual o progresso técnico está incluso, em maiores proporções que o capital variável. "A acumulação capitalista acompanha-se de um aumento de rendimento do trabalho, que se expressa pelo crescimento do capital constante e pela diminuição relativa do capital variável. A parte do capital fixo, isto é, os instrumentos de trabalho cresce mais no capital constante que no capital circulante, ou seja, as matériasprimas". ${ }^{27)}$

\footnotetext{
26 CASTRO, A. B. O capitalismo ainda e aquele. Forense Univ. RJ, 1979. p. $75-90$ coloca que a partir do pós-guerra, o capitalismo entra em nova fase através das yrandes Empresas Modernas. que dispendem elevados recursos em Pesquisas e Desenvolvimento $(P+D)$

27. LAPIDUS \& OSTROVITIANOV, Principios de economia politica, op cit p. 37
} 
O capital adquire cada vez menos trabalho assalariado vivo, a sustentação da mais-valia e cada vez mais trabalho morto, especificamente meios de produção. O trabalho vivo, direto, fonte de valor é substituido pela transferência de valor do trabalho morto, indireto, realizado no passado.

A composição orgânica e a taxa de exploração da força de trabalho desempenham papel fundamental no movimento dinâmico do sistema capitalista. O progresso técnico e o processo de trabalho estão inclusos nestas variáveis. Se o primeiro influi significativamente no aumento do capital constante, o segundo configura-se pela redução do capital variável e na taxa de mais-valia. As implicações expressas nestas relações conduzem na tendência da queda na taxa média de lucro do sistema. O capital não conseguindo se valorizar, entra num processo de crise.

A concentração capitalista, o desenvolvimento das forças produtivas e a resistência dos trabalhadores em lutar contra a exploração de sua força de trabalho conduzem necessariamente ao descenso da taxa média de lucro para uma determinada taxa de mais-valia. Tal comportamento traz consequências diretas para a taxa de acumulação de capital, ao conduzir a uma diminuição na reprodução ampliada e originar a superacumulação de capital. ${ }^{28)}$

O sistema capitalista gera no seu interior a verdadeira contradição. A mesma lei que o conduz a uma valorização do seu capital acaba estreitando a base pelo qual apóia essa valorização. Desenvolve por um lado incessantemente as forças produtivas, prescindindo do valor e da mais-valia, e por outro procura objetivar a conservação e valorização do capital existente.

A competição entre os proprietários dos meios de produção acelera esta contradição. A inovação tecnológica, instrumento de competição, se desenvolve em escala crescente a medida que o capitalismo avança, contribuindo para acirrar esta contradição.

A inovação tecnológica constitui domínio de grandes capitais, que alcançam tal estágio a partir da utilização deste instrumento para absorver outros capitais. $\left.{ }^{29}\right)$ O capitalismo monopolista utiliza-se do superlucro ou renda tecnológica advinda dos ganhos com o progresso técnico para centra-

28 A superacumulação de capital explicada por Marx deriva da queda tendencial da taxa média de lucro O crescimento do capital acumulado, graças à crescente extração de mais-valia encontra cada vez menos possibilidades de investimento que conduzam a uma rentabilidade adequada "A totalidade da mais-valia produzida não é mais suficiente para manter o nivel médio anterior da taxa de lucro" conforme BENAKOUCHE, R. Inflação e crise na economia mundial, Vozes - Petrópolis - RJ, 1981.p. 26.

29 GALVAN, C. G. O processo capitalista de produção e reprodução das disparidades tecnológicas, PIMES -- UFPe - Recife, julho/79, p. 36. 
lizar seu capital. Através da obtenção e taxa de lucro superior à média do setor, alguns capitais criam condições favoráveis para adquirir os impotentes, na disputa tecnológica pelo mercado. " . . . os superlucros são derivados da monopolização do progresso técnico - isto é, de descobertas e invenções que baixam o preço de custo de mercadorias mas não podem (pelo menos a médio prazo) ser generalizados a determinado ramo da produção e aplicadas por todos os concorrentes devido à própria estrutura do capital monopolista".30)

Desta forma, a acumulação e concentração do capital, através do superlucro, colocam quantidades cada vez maiores de capital à disposição das grandes empresas oligopolísticas e monopolísticas. O grande capital procura através da revolução tecnológica diferenciar e combinar setores no mercado externo e especializar e diferenciar os produtos no mercado mundial, para tanto, o capital não só divide os mercados como também penetra através dos conglomerados em diferentes ramos. No capitalismo atual, torna-se difícil encontrar o capital produzindo exclusivamente uma única mercadoria ou atuando especificamente num único setor.

Neste movimento dinâmico, o capitalismo ao impor a revolução científica e tecnológica nos seus meios de produção conduz ao aparecimento de novas características na relação entre o capital e o trabalho.

O capitalismo acelera, segundo Mandel, não somente as inovações tecnológicas, aumentando os custos em pesquisas e desenvolvimento, como altera as duas funções da mercadoria - força de trabalho nas empresas automatizadas. A força de trabalho no sistema capitalista não só cria quanto preserva o valor e no estágio atual, a segunda característica teria mais importância que a primeira. ${ }^{31}$ )

Verifica-se a diminuição do período de produção obtida através da aceleração dos meios de produção na qual conduz o capital fixo a uma vida mais curta. O aumento da velocidade no processo produtivo conduz à ele-' vação no grau de obsolescência das máquinas e equipamentos.

A diminuição da rotação do capital traz implicações física e técnica ao capital. A competição intercapitalista tem conduzido muitos capitalistas a nem terem ainda saldados seus compromissos pela aquisição de determinados instrumentos de trabalho, serem obrigados a substituí-los pelos modelos mais recentes e potentes, já adquiridos pelos seus concorrentes.

30 MANDEL, E, O capitalismo tardio, abril cult. SP, 1983 p. 135.

31 A preservação do valor tem-se constituido nas empresas extrémamente automatizadas a principal função da força de trabalho. O conjunto de máquinas automáticas controladas cibernéticamente exige do trabalhador o manejo correto de seus controles, conforme POLLOCK, F. automation, Frankfurt, 1964. p. 256, 284-285 citado por MANDEL, E. O capitalismo tardio, op. cit. p. 137. 
A rapidez com que ocorre o progresso técnico, exige por um lado, o máximo de produção do capital fixo e, de outro, a intensidade nas vendas das mercadorias produzidas. Tal procedimento reflete a necessidade do capi-, talista obter retorno o mais rápido possível, dado a incerteza do perlodo de vida útil deste capital.

A detenção do poder de criação das inovações tecnológicas, estão concentradas nas mãos do grande capital, que direta e indiretamente procura assegurar esta posição.

O argumento neoclássico de que a economia se apresentaria com inúmeras firmas, livre entrada de concorrentes e não existência de descontinui. dade tecnológica são considerados inverídicos no capitalismo moderno. $O$ próprio Labini rompeu com estes postulados marshalianos.

Esboça o raciocínio de que o sistema produtivo capitalista não permite a possibilidade constante de entrada de novas firmas e a rápida difusão tecnológica, possibilita os grandes capitais manterem por períodos prolongados diferenças de custos que fortalecem suas posições nu mercado.

Os frutos do progresso técnico implícitos nas reduções dos custos produtivos são distribuídos somente a uma classe portadora dos meios de produção e o próprio sistema incumbe de discriminar o acesso aos demais. Labini afirma, ". . esta observação, já foi substancialmente tratada por Marx. Sabe-se que as dificuldades de obtenção de empréstimos e disposição de fundos são muito menores no caso das empresas muito grandes do que no das empresas médias, pequenas e ainda de novas empresas"32) que querem buscar um volume de capital para alterar sua estrutura técnica.

A inovação tecnológica, não sendo acessível a todos os capitalistas, não redundará em reduções de preços e sim em elevação da margem de lucro. O progresso técnico permite que os grandes capitalistas obtenham superlucro, com a redução dos custos no processo de trabalho.

A solidificação destes ganhos é consolidada com a criação de barreiras à entrada, físicas e legais, a possíveis concorrentes.

O capitalista cria mecanismos que impedem o aparecimento de concorrentes que venham abalar sua posição no mercado. Dentre estas, podem ser citadas, os elevados investimentos requeridos no processo de trabalho, controles de patentes, enormes custos de publicidade e influências nas decisões legais do Estado para benefício próprio. Entretanto, acima de qualquer

32 LABINI, S. Oligopólio e progresso técnico, Forense Univ. - USP - SP. 1980, p. 42. 
barreira criada pelo capital, passa-se o domínio sobre o próprio avanço tecnológico, que a priori, é reservado a um número restrito de capitais. ${ }^{33}$ )

A disputa na revolução científica e tecnológica dos meios de produção, reforça cada vez mais a posição hegemônica alcançada pelos grandes capitais. ". . o capitalismo moderno, em muitos ramos importantes caracteriza-se por um processo de expansão do tamanho de um número relativamente decrescente de empresas, o que determina um processo de concentração; e o principal fator condicionante desse processo é o progresso técnico" 34 )

O poder capitalista ultrapassa os limites dos Estados nacionais. O capital ao mover-se internacionalmente na busca incessante de lucro, conduz o controle cada vez mais centralizado das inovações tecnológicas. Os oligopólios, grandes blocos do capital internacional são os que têm condições de apresentar funções inovadoras nas economias, ao fazê-las, desenvolvem tecnologias voltadas para o interesse próprio e para assegurar a manutenção e reprodução das relações sociais existentes.

\section{CONCLUSĀO}

O sistema capitalista revolucionou o progresso técnico e o processo de trabalho. As transformações ocorreram gradativamente passando pela cooperação, manufatura até alcançar a fábrica moderna. Nesta última, culmina com o inverso do in ício do processo. "O instrumento de trabalho deixa de ser expressão de atividade subjetiva do trabalhador para se transformar na expressão personificada do capital que utiliza o trabalhador como seu instrumento". ${ }^{35)}$

No estágio atual do capitalismo, o processo de trabalho é marcado por um controle na hierarquia produtiva, com o capital delegando poderes àqueles que respondem em seu nome, pela submissão do trabalhador aos instrumentos de trabalho e pela separação entre a mente e o coração da fábrica.

O regime de produção capitalista, separou o trabalho manual do intelectual e retirou os instrumentos das mãos habilidosas do trabalhador para ser produzido segundo os interesses do capital.

\footnotetext{
33 Segundo levantamento feito por RATTNER, H em seu artigo Ciencia e Tecnologia: as tendèncias atuais in Economia \& Desenvolvimento, Cortez Edit SP 1982. p. 67, o progresso técnico está centralizado nas mãos de menos de 200 grandes corporações que controlari nos EUA cerca de $75 \%$ do investimento no exterior, na RFA controlam cerca de $70 \%$ e $80 \%$ no Reino Unido

34 LABINI,S Progresso técnico, preços e crescimento uma introduçäo in Pragresso técnico e teoria econômica, Hucitec.Unicamp - SP 1980, p 75

35 BELLUZZO L G. A transfiguração critica in Estudos Cebrap. ed Cebrap SP, no 24, p 21 e 22
} 
A coletivização do processo de trabalho estende além dos limites da fábrica e engloba todo circuito produtivo. Torna-se impossível determinado setor funcionar isoladamente em relação aos demais setores produtivos da socieade capitalista.

A penetração do progresso técnico nas instâncias da produção conduziu por um lado, no crescimento da população trabalhadora excedente e, de outro, na diminuição do valor de troca da força de trabalho.

A tendência destas características se agravam, principalmente com a intensificação da microeletrônica nos processos de trabalhos, contribuindo para aumentar o exército de reserva e segregar tal processo a um grupo restrito de trabalhadores intelectuais.

A lei de acumulação impõe este regulamento aos capitalistas. Os que não transformarem suas bases técnicas serão eliminados desta transformação. O superlucro ou renda tecnológica, advindo constitui substancial ganho para acelerar o processo de concentração e centralização do capital.

Neste sentido, expressa-se o principal objetivo da automação do processo de trabalho, a diminuição do tempo socialmente necessário e a extorsão crescente da mais-valia relativa. O crescimento do trabalho não pago possibilita a valorização do capital.

A medida que o capitalismo avança neste processo, ocorre a diminuição constante do trabalho vivo e o aumento contínuo da composição orgânica do capital. O aumento progressivo do capital constante em relação ao capital variável conduz à superacumulação, implicando no declínio da taxa de lucro. A tendência declinante da taxa de lucro constituiu uma reação contrária ao movimento de acúmulação de capital. No seu movimento de expansão, o capital tende a desconsiderar a base, o sustentáculo que lhe permite o seu próprio processo de valorização.

A partir desta tendência, o capital acirra a competição. Ao conduzir a internacionalização da estrutura produtiva para reverter tal comportamento o capital institui a inovação tecnológica como o seu principal instrumento de luta.

Assim sendo, no capitalismo moderno, o progresso técnico e o processo de trabalho colocam de um lado, o capital, diminuindo o tempo de sua rotação e a sua sobrevivência, e de outro o trabalho, aumentando a despersonalização da força de trabalho e acirrando as contradições sociais.

Neste sentido, o capital, constantemente altera sua base produtiva, mas mantém constantemente inalteradas suas relações econômicas e sociais, em consonância com as palavras de Marx. 